\title{
UM JOGO DE REPRESENTAÇÕES: O FUTEBOL SUBURBANO NOS JORNAIS DA CIDADE DO RIO DE JANEIRO (DÉCADA DE 1910)
}

\author{
Nei Jorge Santos Junior \\ Universidade Federal do Rio de Janeiro, Rio de Janeiro, Rio de Janeiro, Brasil
}

\begin{abstract}
Resumo
Esse artigo tem por objetivo discutir as representações dos clubes suburbanos na imprensa carioca da década de 1910, procurando demonstrar os seus múltiplos sentidos e diferentes significados. Para alcançar o objetivo proposto, iniciaremos discutindo as representações sociais sobre o futebol suburbano em jornais da grande imprensa, buscando entender as possibilidades de resistência durante os jogos e o grau de inter-relações criados em meio a toda pluralidade de experiências. Por fim, motivado pelo recorte espacial e temporal desse estudo, buscamos compreender a relação estabelecida entre os clubes do subúrbio e os periódicos da região.

Palavras-chave: Futebol. Jornais. História.
\end{abstract}

\section{Introdução}

$\mathrm{O}$ s primeiros momentos do futebol no Rio de Janeiro foram marcados por uma série de interesses e representações que relacionavam o esporte inglês à formação de um novo modelo de cidadão. Inicialmente presente no âmbito das elites - pelo menos enquanto possibilidade de prática -, o moderno esporte bretão orientava-se pelos valores do cavalheirismo, do fair-play, e do amadorismo, elementos indispensáveis para uma sociedade em que adotava o modelo europeu como parâmetro cultural para a recém-instaurada República brasileira.

Contudo, ainda na primeira década do século XX, o esporte come-

1-Alguns exemplos de novos clubes que se espalharam pela cidade: Bangu Athletic Club (1904), Sport Club Mangueira (1906), Brasil Athletic Club (1906), Cascadura F. C. (1906), Club Atlético Méier (1906), Esperança Athletic Club (1907). Andarahy Athletico Club (1909). 
çava a sentir as ambivalências do momento. A sua difusão pelos mais distintos bairros do Rio de Janeiro ${ }^{1}$ desencadearam conflitos ao redor da imagem de distinção social desejada pelos sportsmen vinculados aos clubes frequentados pelas elites cariocas ${ }^{2}$. Tratava-se de um número cada vez maior de negros, operários e indivíduos das camadas populares, que incomodava àqueles que revestiam a modalidade, pelo menos discursivamente, de um caráter "civilizacional" superior.

Esses novos personagens, tanto a torcida quanto os jogadores, adotavam certos comportamentos que, no olhar dos setores sociais mais privilegiados economicamente, eram considerados lamentáveis. Essa mudança de sentidos reforçava um fator ideológico, já que as páginas dos principais periódicos da cidade deixavam de celebrar a sofisticação e a fidalguia para declarar a desmoralização e o repúdio pela prática nos centros mais pobres da cidade. Buscava-se, portanto, no comportamento desses sujeitos, ações que diferenciassem das propostas idealizadas pelos sportsmen, reproduzindo, efetivamente, um conjunto de reações extraídos das agremiações da Zona Sul.

Considerando que estas manifestações são expressões das tensões observadas no processo de consolidação do futebol no Rio de Janeiro, bem como de uma ordem social que tentava manter privilégios para determinados grupos, esse artigo tem por objetivo discutir as representações dos clubes do subúrbio na imprensa carioca da década de 1910, procurando demonstrar os seus múltiplos sentidos e diferentes significados.

Para alcance do objetivo, pretendemos utilizar duas estratégias distintas e complementares. Inicialmente discutiremos as representações sobre o futebol suburbano em jornais da grande imprensa (Correio da Manhã, Jornal do Brasil e O Imparcial). No segundo momento, motivado pelo recorte espacial e temporal desse estudo, trabalharemos com o Bangú-Jornal, na tentativa de compreender a

2- As elites eram formadas por aqueles que detinham o poder econômico, político e cultural, constituídas tanto pelos proprietários dos meios de produção quanto pelo que pode ser chamado de setores médios ou pequena burguesia. Inicialmente, eram os nobres, políticos e aristocratas ligados à economia agroexportadora. Posteriormente também a integraram os setores urbanos, como militares de alta patente, envolvidos com o alto comércio e indústria, além de parte de intelectualidade. 
multiplicidade de conflitos existentes dentro do lócus suburbano.

\section{Entre tiros e pauladas: representação dos clubes do subúrbio na grande imprensa carioca}

No dia 23 de novembro de 1919, os principais jornais cariocas anunciavam com sentimento de cólera a interrupção do match entre o Andarahy e o Vila Isabel. No final do primeiro tempo, após um choque entre um jogador de cada time, a torcida do primeiro invadiu o gramado. Depois de muitas pauladas, tiros e navalhadas, a polícia pediu reforços e conseguiu dar fim ao tumulto, com a prisão de alguns envolvidos.

Dois dias após o incidente, O Imparcial publica uma carta do árbitro da partida, Max Eckstein, em que relatava com indignação os atos de violência de alguns torcedores do Andarahy:

As "torcidas", covardemente, se dirigiram para a porta de minha residencia, sabendo-me no campo do Jardim Zoologico e minha senhora sozinha, sem que nada soubesse, foi ameaçada por mais de 40 indivíduos, alguns mostrando punhais e revólveres, que, além disso, deram assustadoras noticias a meu respeito, entre ellas, que eu tinha sido navalhado e aguardava em campo os socorros da assistência.

Se não fossem as garantias prestadas pela policia local, a pedido de minha esposa, que para lá mandou uma "viuva alegre" e duas praças de cavallaria, não sei de que seriam capazes os audazes indivíduos, que, por infelicidade, são "torcidas" do Andarahy (UMA CARTA..., 1919, p. 10).

Para o árbitro, tal violência não se justifica, inclusive porque atuara com lisura e eficiência. Para ele, "a explosão da assistência só pode ser atribuída ao fanatismo cego de certos indivíduos, que não conhecem as regras de football e muito menos de educação" (UMA CARTA..., 1919, p. 10).

No mesmo dia, o vice-presidente do Andarahy, Antonio de Miranda, publicou uma nota oficial desmentindo essas informações.

A directoria do Andarahy A. C, a bem da verdade, vê-se na contingência de desmentir o chronista do matutino do Largo da Carioca, quando se referiu, em sua edição de hontem, ao match e conflicto havido no campo do Jardim Zoologico. 
Assim contesta ella, por não ser verdade:

Que tivesse sido chamada para depor em qualquer delegacia de polícia; que tivesse havido navalhadas no campo de football; que tivesse sido o autor do conflicto seu associado Gilabert, tendo em vista que o mesmo chronista attribue na mesma descripção do seu jornal a autoria da aggressão e causa do referido conflicto á outra pessoa que se julgara chargeada por ser um adversário (UMA NOTA..., 1919, p. 11).

Essas declarações são indícios do conflito simbólico que se estendeu por anos no cenário do futebol carioca. Se por um lado esses acontecimentos explicitavam a força do ethos existente entre torcedores e suas agremiações, por outro fortaleciam a estigmatização.

Por exemplo, nas palavras de Mario Pollo, cronista do Correio da Manhã, essas agremiações seriam responsáveis por afastar dos estádios as "boas famílias cariocas", que não se conformariam em ver essa situação "absolutamente incômoda e desagradável" (POLLO, 1916, p. 9). Na maior parte das vezes, era assim que os clubes do subúrbio eram retratados nos periódicos cariocas, todavia, se eram inegáveis os conflitos, também o eram os preconceitos.

Vejamos, por exemplo, a narração do jogo entre o Bangu e o Fluminense, realizado em junho de 1917. São explícitos os estereótipos usados pelo cronista, que não enxergava, nos sócios das agremiações do subúrbio, o refinamento desejado para a sociedade carioca.

No longínquo campo do Bangu A. C., realizou-se, ontem, o embate entre os teams desse club e os do sympathico Fluminense F. C.

O querido club da rua Guanabara conseguiu, ontem, brilhantemente, coisa que, o anno passado, não succedia com os teams que demandavam aquelle campo, derrotar o valoroso Bangú.[...]

Como referee actuou o Sr. A. Almeida cuja actuação desgostou os partidários do club local, os quais tentaram aggredil-o.

O jogo desenvolvido pelo team local foi violento como sempre, tendo sahido machucados os players Lais e Emmanuel do Fluminense.

A liga precisa, quanto antes, tomar séria providencia para que 
não tenhamos muito em breve de ver aleijados em nossos campos, pelos jogadores "vallentes", aquelles que procuram no football um divertimento.

Das vítimas de hontem em campo, Emmanuel foi quem mais soffreu, tendo se recolhido á residência de seus progenitores, onde está em tratamento, com um dos braços desarticulado.

Ao deixar a estação de Bangú o trem especial do Fluminense no qual vinham muitas famílias, foi apedrejado por um grupo de desordeiros.

Felizmente a não serem as vidraças quebradas não se verificou nenhum desastre pessoal. Coisas do Football (O FLUMINENSE..., 1917, p. 8).

Observam-se nesta citação dois pontos importantes que merecem ser explorados. O primeiro é a elogiosa referência ao "sympathico Fluminense F. C.", "o querido club da Rua Guanabara", que teria sido vítima de todos os descalabros. A admiração do cronista d'O Impacial era observada também em outros órgãos da grande imprensa. Para essa agremiação, constantemente eram dedicados elogios e sinais de reconhecimento. Essa equipe da Zona Sul, que sempre teve entre seus sócios e frequentadores representantes das famílias economicamente mais prósperas da cidade, simbolizava os "tempos áureos" do jogo, algo que, supostamente, não era mais encontrado dada a presença de jogadores oriundos da periferia.

O segundo ponto é a sugestão de que eram comuns condutas violentas nos jogos do Bangu, especialmente quando a partida se realizava em seu "longínquo" campo. Ao contrário do Fluminense, para o clube do subúrbio poucos elogios havia. Seus jogadores e sócios eram somente reconhecidos por suas supostas posturas inadequadas. Afinal de contas, o clube suburbano, que tinha entre seus "mais ardorosos torcedores desocupados", seria o único responsável pelos fatos criminosos que acontecera com frequência ao final de seus jogos.

Dois dias após, o presidente do Bangu A. C., Sr. Noel de Carvalho, enviou uma carta ao jornal O Imparcial, indignado com o tratamento injusto e agressivo que o clube vinha recebendo da grande imprensa carioca. De acordo com o Sr. Noel, sempre que a imprensa carioca se refere ao seu clube, do qual sente muito orgulho de pertencer, o trata de um modo injusto e agressivo, no qual "transparece não o desejo de pugnar pelo engrandecimento e moralidade do Sport, mas tão somente 
a intenção de amesquinhar esse modesto núcleo de cultura physica" (OS ACONTECIMENTOS..., 1917, p. 8).

Decerto, Noel atingia o cerne da questão. Lamentava que os responsáveis pelas seções esportivas estivessem obcecados pelos "preconceitos sociais", que os levaria analisar por prismas diversos factos, "já quando estes se apresentam no meio do elemento operário, já quando estes surgem no coração da "elite", no meio daqueles mais favorecidos pela fortuna" (OS ACONTECIMENTOS..., 1917, p. 8).

Obviamente que o presidente da agremiação banguense ameniza os fatos ocorridos, sem, contudo, negá-los: "a diretoria do clube, com o prestígio de que goza e de que se ufana, conteve prontamente esse movimento, e irá corrigir aquelles que promoveram" (OS ACONTECIMENTOS..., 1917, p. 8); os fatos receberam a reprovação da "unânime dos sócios do Bangú e da população local". Por essa razão, o que se passou "foi fructo dessa criançada irrefreável, que prolifera em toda a parte, dessa garotada anonyma, desses 'gavrochés' infernais, irreprimíveis e quase impalpáveis, quando se pretende corrigi-los" (OS ACONTECIMENTOS..., 1917, p. 8). Ainda assim, o presidente contestou que o bairro não era uma região "habitada por selvagens ou botocudos" (OS ACONTECIMENTOS..., 1917, p. 8), mas sim uma localidade "laboriosa e de população pacata".

Em resposta, o jornal encerrou a coluna concordando com as declarações do "illustre presidente do Bangu", mas salientando que,

felizmente, a maioria dos jornais, registrando o fato o se revestiu da maior gravidade, não envolveu na sua censura, nem a diretoria, nem os heroicos players do valoroso alvirrubro, que, como nós lamentamos que o entusiasmo dos seus torcedores a tanto os tivesse levado (OS ACONTECIMENTOS..., 1917, p. 9).

Certamente, as palavras utilizadas pelo cronista não eram convincentes; o descaso e o preconceito com os clubes da zona suburbana continuava sendo uma constante. Eram repetidas as notícias que depreciavam a moral de seus componentes, não poucas vezes estabelecendo uma relação linear com sua condição social. Esse tipo de postura não era uma novidade no Brasil, sendo muito próxima àquelas observadas ao se noticiar a "loucura mística" de Antonio Conselheiro, a ignorância e imundície dos moradores dos cortiços cariocas e a subversão e desordem das organizações proletárias (Franco Júnior, 2007). 
Vejamos um exemplo:

Ainda hontem no campo do Bangu A. C., por occasição do encontro dos teams locaes com os do S. Christovão, registraramse factos que são tão indignos, que mais mereciam ser lamentados numa secção policial.

Faltando 22 minutos para terminar o encontro Patrich perdendo a pelota para Hugo aggride este jogador no que é repellido.

Estabeleceu-se o tumulto, que teve como conseqüência a invasão do campo, novas aggressões, pauladas, revolvers e navalhas em scena e.. suspensão do jogo!

Não sabemos ainda quaes os culpados de tamanha falta de educação: se os desordeiros da Favella ou se os agressores do Morro Pinto.

Francamente, srs. Sportmen. Isto nunca foi football! Acabemos com estas scenas lamentáveis, antes que a policia prepare um logar seguro para serem trancafiados os desordeiros que se querem impingir como sportmen! (O ENCONTRO..., 1919, p. 8)

Ao descrever que "infelizmente o nosso football ainda não está de todo civilizado", o cronista parecia esquecer que o excesso desses conflitos não era uma exclusividade dos clubes sediados nas regiões mais pobres da cidade. Vendo nos seguidores dessas agremiações os principais responsáveis pela desmoralização do futebol, ele lamentava a "perniciosa" mistura social, uma perda irreparável, causada pela índole natural dos novos admiradores do jogo (PEREIRA, 2000).

Em seu estudo sobre o cotidiano das camadas populares, Chalhoub (2001) nos ajuda entender porque o registro dos conflitos entre sócios e torcedores dessas agremiações era tradicionalmente abordado sob o estigma de "desordeiros da Favella" ou de "agressores do Morro". Para os teóricos da patologia social, a pobreza produziria a ausência de normas ou a falta de padrões de comportamento. Por estas razões, a racionalidade intrínseca aos diferentes tipos de comportamento não saltava aos olhos dos teóricos, preocupados em analisar as reações a partir dos padrões que lhes eram extrínsecos, tentando impingir padrões de comportamentos extraídos das classes mais bastadas, nesse caso, das agremiações da Zona Sul.

Dessa forma, embora alguns torcedores reivindicassem contra "as 
acusações injustas" que atingiam "um povo laborioso e, sobretudo, honesto como é o Bangu", eles eram vistos como os principais suspeitos de quaisquer desordens que viessem a acontecer em seus jogos (Pereira, 2000). Por isso, a cada partida marcada, a própria polícia se apressava em reforçar o patrulhamento local, na tentativa de conter os ânimos dos torcedores dessas agremiações. A liga Metropolitana, por sua vez, mandava frequentemente ofícios aos clubes da zona suburbana, pedindo-lhes que tentassem evitar o contato dos jogadores com seus torcedores, buscando proteger os visitantes da propagada fúria local.

De fato, a estigmatização fica ainda mais clara quando comparada aos conflitos causados por clubes da elite carioca. Por exemplo, um tumulto na partida realizada entre América e Botafogo, em 1914, foi apresentado como mero fruto do amor dedicado ao clube. Por vezes, até mesmo os incidentes ocorridos nos campos das equipes mais tradicionais, com a total participação dos seus sócios, eram atribuídos aos torcedores "impertinentes e mal educados" do subúrbio (Pereira, 2000). Na visão de redatores, não havia dúvidas: eles possuíam o monopólio da falta de educação esportiva.

Vejamos outro curioso exemplo. No campeonato de 1922, os conflitos observados em jogo entre o América e o Flamengo foram assim comentados:

Uma vez que nos referimos às brigas entre os assistentes, provocadores de arruaças que, comumente se verificavam, hoje, dá-se justamente o contrário. Os moleques, os arruaceiros, os que provocam brigas e barulhos que exigem a acção immediata da policia, ficam justamente entre o publico que se aglomera nas archibancadas, ao passo que nas geraes reina uma ordem nunca vista.

Somos justos: a gente melhor fica hoje nas geraes... Se só é nas archibancadas que se briga, que se agride, que se offende os juízes... (OS MATCHES..., 1922, p. 7).

Essas declarações, excepcionalmente contrárias às elites, provocou uma reparação na edição do dia seguinte. Tentando corrigir o que afirmara, o cronista declara que, "de tal modo como ficou dito", pareceu que os conflitos aconteciam "somente entre os que estão nas archibancadas do sympathico club da Rua Campos Salles" (DA GERAL..., 
1922). Com a justificativa de não ter citado qualquer agremiação, o cronista alegou que entre as brigas "salientam-se as que se originam nas archibancadas, ao passo que os assistentes das geraes tem tido um comportamento não confirmados do conceito máo em que eram tidos" (DA GERAL..., 1922).

A retratação feita pelo Correio da Manhã revelava uma preocupação em não comprometer imagem desses dois clubes. Sendo, em sua maioria, filhos de figuras importantes entre os círculos mais nobres da sociedade carioca, seus escândalos e problemas sequer eram noticiados, explicitando o desconforto em noticiar os conflitos existentes entre os clubes mais tradicionais da cidade.

Um dos que na própria imprensa observou esse tratamento diferenciado foi Lima Barreto. Em artigo publicado na revista Careta, de 1 de janeiro de 1921, o literato pôs em discussão a notícia veiculada pelo jornal A Noite, em 13 de dezembro de 1920, na qual expôs um conflito entre as equipes do Mangueira e do Fluminense. Para o cronista, não era somente nos campos dos clubes de "terceira ordem" que tais cenas se verificam, nas agremiações das elites "também se tem timbrado nesses desrespeitos à assistência, não atendendo sequer á presença de senhoras, que são atropeladas nas correrias e até agredidas, devido á confusão" (BARRETO, 1921, p. 5).

Numa posição contrária, Lima Barreto observava que "trancos e pontapés" eram típicos dos jogos. Por essa razão se perguntou: por quais motivos "clubs aristocratas e puros" seriam distintos dos "clubezinhos do subúrbio? O football é uma e mesma coisa em toda parte!" (BARRETO, 1921, p. 5).

De fato, as práticas estabelecidas pelos jornais da época contribuíam para a construção de representações sociais das agremiações da zona suburbana, pois, do mesmo modo em que realizavam as intermediações entre realidades, por outro lado, ofereciam uma interpretação sobre determinado fato e/ou acontecimento, apesar dos discursos de imparcialidade. Além disso, esses periódicos também efetuavam a divulgação de ações inexistentes. Ao utilizar uma imagem em detrimento de outra, ou ao privilegiar uma fonte de informação, escolhas eram feitas e é justamente este procedimento que iria culminar na apresentação de um ponto diferente.

Para compreender como os estereótipos influenciaram diretamente nesse processo, recorremos aos estudos de Ferrés (1998) sobre o tema. De acordo com o autor, os estereótipos são representações sociais, 
institucionalizadas, reiteradas e reducionistas e, por essa razão, tratase de representações, que conjecturam uma imagem compartilhada que um coletivo possui sobre o outro, transformando uma realidade complexa em algo simples. A partir desse ponto, percebe-se a necessidade de manusear fontes que expressam o cotidiano desses sócios e torcedores. Essas fontes - jornais locais e atas dos clubes - ajudariam a entender uma espécie de resolução por regras de comportamento próprio, o que nos permite pressupor a inexistência de elementos ordenadores das relações pessoais do cotidiano desses torcedores.

\section{O futebol suburbano nas páginas da imprensa local: o caso do Bangu-Jornal}

A intenção de produzir um jornal engajado na tentativa de "recrear, instruir e advogar os interesses suburbanos" (COM LICENÇA, 1883, p. 1) expressa, desde a década de $1880^{3}$, diferentes indivíduos, em diferentes espaços, na luta por melhores condições de vida, trabalho e lazer. Esse discurso, presente na maioria dos periódicos suburbanos, fazia-se valer pela necessidade de criar vínculos com o bairro de origem. Nesse momento, ter um número expressivo de assinantes significava dar continuidade aos seus propósitos e, por isso, contar com o apoio de moradores e comerciantes da região era algo mais que necessário (MENDONÇA, 2011).

Para alcançar tal relação, seus editores enxergaram no futebol um importante objeto na construção de elos de sociabilidade, passando a incorporar, regularmente, os resultados dos campeonatos e a programação dos clubes do subúrbio em suas páginas. Dessa forma, o antigo esporte bretão se tornava, mesmo longe de poder ser definido como um símbolo de identidade local, um relevante elemento na interface entre os jornais e os leitores (SANTOS JUNIOR, 2012).

De fato, seus redatores atribuíram um novo significado ao discurso de refinamento e fidalguia construído pelos primeiros sportsmen. Distante das práticas estabelecidas pelos grandes jornais da época, suas notícias não corroboravam com a construção de estigmas e representações sociais criadas pela grande imprensa carioca (SANTOS JUNIOR; MELO, 2013). Pelo contrário, os cronistas precisavam

3-Podemos citar a COM LICENÇA... (1883), SUBÚRBIOS... (1895), ATENÇÃO (1900), entre outros. 
estabelecer uma relação com a população local, conquistar este leitor, ganhar sua confiança e fidelidade para poderem se candidatar ao posto de guias de suas opiniões e intérpretes de sua vontade. Dessa forma, defender os interesses da localidade, tal como destacar as suas conquistas, indicava a estratégia que tornava possível criar uma identificação imediata com os moradores da região. Vejamos, por exemplo, a matéria publicada pelo Bangu-Jornal.

O segundo domingo de julho de 1918 foi de revolta nos arrabaldes de Bangu. A seção "Vida Sportiva" publicou uma matéria sobre a suspenção dos jogos no estádio banguense. A interdição, de acordo com a nota emitida pela Liga Metropolitana, foi resultado da violência presente nos jogos do clube, considerado pelo cronista como "injusta e arbitrária" (VIDA SPORTIVA, 1918, p. 3). Indignado com a medida, a equipe do jornal expressou sua insatisfação nas páginas do periódico. Para o autor, "a injusta medida", causava enormes prejuízos materiais ao "valoroso club", sem contar com a falsa superioridade colocada nos relatórios, fazendo alusão aos "dignos membros da apaixonada diretoria” (VIDA SPORTIVA, 1918, p. 3).

De fato, o recado já havia sido dado. Um número significativo de ofícios, discutindo a violência nos jogos, foi enviado aos representantes da equipe arrabaldina. Talvez, por esperar uma medida mais drástica, o cronista adiantou: "ao que sabemos, as responsabilidades da Liga já se acham bem apuradas no judiciário e em breve será proposta uma acção contra a mesma pedindo uma forte indenização por perdas e dannos" (VIDA SPORTIVA, 1918, p. 3).

Nesse caso, mover uma ação na justiça contra a aristocrata Liga Metropolitana seria, nas palavras do autor, "uma boa e bastante aproveitável licção para os despeitos da Liga e uma estupenda victoria moral para o nosso querido club" (VIDA SPORTIVA, 1918, p. 3). Essa iniciativa seria "uma boa e bastante aproveitável licção para os despeitos da Liga e uma estupenda victoria moral para o nosso querido club". Tal postura era lida como uma forma da região fazer-se respeitar.

O Correio da Manhã não deixou de comentar a "petulante ousadia de perturbar a doce paz dos nossos amigos da liga Metropolitana" (A REUNIÃO..., 1918, p. 6). Já A Época informava que:

o representante do Bangú desmentiu categoricamente que seu club pretendesse chamar a juízo a L.M.D.T, para ser indenizado 
pelas perdas a dannos decorrentes da interdição do campo da mesma sociedade. Ainda bem... (O TÓPICO, 1918, p. 9).

Em resposta, o Bangú-Jornal afirmava que, "decididamente, nem bem viu a luz do dia, e já está em foco o nosso modesto semanário" (BANGU, 1918, p. 3). Em relação à versão noticiada pelo jornal A Epoca, o cronista responde textualmente, "os leitores bem conhecem o valor significativo das "reticências" que sempre envolvem dúvida, ironia, malicia... etc" (BANGU, 1918, p. 3). Por outras palavras, o autor afirmava estar com a razão, "mas quando isso não se verifica, parece-nos que o seguinte período da nossa honra bastava para dar ao caso as grandiosas proporções que se dá a uma notícia não confirmada - à um consta" (BANGU, 1918, p. 3). A fim de esclarecer expôs dois pontos que mereciam a atenção:

a)

Pelos processos regulares e perante autoridades competentes, depuseram pessoas qualificadas para se apurar as responsabilidades do referee que presidiu o jogo e que apresentou á Liga o relatório que deu causa á interdição do campo.

b)

Chamado o referee á depor, defendeu-se, negando o facto principal: Logo... atirou "com as responsabilidades" para a Liga rendendo uma sincera homenagem já verdade, o nosso illustre contradictor será capaz de negar, ou por outra, de desmentir o exposto?

Não cremos, mas si for, falaremos mais claro ainda... (BangúJornal, 21 de julho de 1918, p. 3)

Por essas razões, percebe-se a vontade em revelar, minuciosamente, às ações que o levou a denúncia. Com um tom irônico, o autor questionava a atuação tímida da diretoria do Bangu. Para ele, "o nosso valoroso club local" não poderá se orgulhar se:

n'um gesto digno e nobre e tendo um presidente honrado (todo feito de paz e amor) sujeitar-se a todos os prejuízos sofridos, conformando-se apenas com a desaffronta que sua altiva directoria conseguiu em processo regular, e desistindo de chamar a Liga às contas. (BANGU, 1918, p. 3). 
De fato, o periódico local exaltava, defendia, mas também cobrava. Recuar não dignificava os "valorosos rapazes do club", pelo contrário, permitir-se-ia que a Liga seguisse utilizando artifícios para neutralizar os clubes do subúrbio, de forma que "suas injustiças (tomara que não se reproduzam - é sempre melhor) consigam as mesmas condescendências..." (BANGU, 1918, p. 3).

É curiosa, desse modo, a relação estabelecida entre os clubes do subúrbio e os periódicos da zona suburbana. A postura destes, diferentemente dos demais órgãos da grande imprensa, expressava sem delongas a ligação íntima com os clubes da região. Possivelmente, o motivo dessa intensa conexão fosse pelo fato de vivenciarem o cotidiano local. Se recorrermos a alguns conceitos abordados pela Geografia, o local ocupa papel central nas relações do indivíduo, visto que através dele se articulam as experiências e vivências do espaço. Consequentemente, o local envolve fortes elementos subjetivos ligados à racionalidade humana, como a identidade, a percepção, a cultura, a memória e o sentimento de pertencimento, ligados aos valores e aos sentimentos do homem em relação a um fragmento do espaço que possa ser vivenciado e experimentado.

De acordo com Relph (1996), o processo de desenvolvimento de uma identidade local seria uma combinação de observações, isto é, o contato direto com o local e as expectativas estabelecidas antes deste contato. Dessa forma, a região seria um centro de significações insubstituível para a formação de nossa identidade como indivíduos e como membros de uma comunidade. Para o autor, uma relação profunda com os lugares é tão necessária, e talvez tão inevitável, quanto uma relação próxima com as pessoas; sem tais relações, a existência humana, embora possível, fica desprovida de grande parte de seu significado (RELPH, 1980).

Para compreender essa relação, é necessário conhecer um pouco mais o universo da zona suburbana: suas dificuldades, suas reivindicações e a luta por melhores condições de vida. A leitura de periódicos da zona suburbana, por exemplo, ajudariam a entender uma espécie de resolução composta por regras de comportamento próprio, revelandonos importantes pistas sobre as estratégias cotidianas daqueles atores. 


\section{Considerações finais}

De fato, percebemos que os jornais foram agências centrais na construção de representações sociais sobre as agremiações do subúrbio da cidade. Como lembra Moscovici (2004), a representação social desponta no momento em que existe ameaça para a identidade coletiva, quando o cojunto de conhecimentos submerge as regras que a sociedade se outorgou. Foi nesse cenário que o discurso produzido por esses jornais perpassavam pela objetividade e subjetividade.

A grande imprensa, por exemplo, procurava estabelecer restrições às agremiações da zona suburbana. Uma das iniciativas foi a instituição de regulamentos que destacavam a violência e o desserviço prestado ao futebol. Travava-se de uma noção particular de subúrbio, enraizado por estigmas fortemente marcados pela estratificação socioespacial da cidade. A partir dessa descontextualização e recontextualização, o jornal traduzia sua visão de mundo, impregnado por estigmas que desqualificavam não só torcedores e jogadores, como também o território em que eles ocupavam e habitavam. Por um lado, se essas ações eram indícios do conflito simbólico que se estendeu por anos no cenário do futebol carioca, por outro, acreditamos que explicitavam a força do ethos existente entre torcedores e suas agremiações.

Naturalmente, os clubes mais populares não ficaram inertes frente a esse processo. Não só procuraram contestar na própria grande imprensa as acusações, denunciando mesmo o trato injusto e desigual dos periódicos, como por vezes contaram com o apoio dos jornais de bairro, que não tinham o mesmo poder, mas logravam certa repercussão local.

$\mathrm{Na}$ verdade, parece possível apontar a necessidade de manusear mais cuidadosamente fontes que melhor expressem o cotidiano desses sócios e torcedores a partir de seus próprios pontos de vista. Jornais locais e atas dos clubes, por exemplo, ajudariam a entender importantes pistas sobre as estratégias cotidianas daqueles atores. Esse tipo de abordagem poderia certamente contribuir para tornar mais múltiplos e diversos nossos estudos e nossa compreensão sobre o futebol brasileiro, que não foi somente uma obra das elites, mas sim um constructo em que também as periferias participaram ativamente. 


\title{
REPRESENTATIONS OF A PLAY: THE SUBURBAN FOOTBALL IN THE NEWSPAPERS IN THE CITY OF RIO DE JANEIRO (DECADE OF 1910)
}

\begin{abstract}
This article aims to discuss the representations of the clubs in the suburb of Rio press in the 1910s, seeking to demonstrate their multiple meanings and different meanings. To achieve our objective, we will begin discussing the social representations about football suburban newspapers in the mainstream press, seeking to understand the possibilities of resistance during the games and the degree of inter-relationships created in the midst of plurality of experiences. Finally, motivated by the spatial and temporal clipping of this study, we sought to understand the relationship between the clubs and the Periodicals suburban region.
\end{abstract}

Keywords: Football. Newspapers. History.

\section{UN JUEGO DE REPRESENTACIONES: EL FÚTBOL SUBURBANO PE- RIÓDICOS EN LA CIUDAD DE RIO DE JANEIRO (DÉCADA DE 1910)}

\section{Resumen}

Este artículo tiene como objetivo discutir las representaciones de los clubes en los suburbios de Rio de prensa en la década de 1910, tratando de demostrar sus múltiples sentidos y significados diferentes. Para lograr nuestro objetivo, vamos a empezar a discutir las representaciones sociales acerca de los periódicos suburbanos de fútbol en la gran prensa, tratando de comprender las posibilidades de resistencia durante los juegos y el grado de inter-relaciones creadas en el medio de la pluralidad de experiencias. Por último, motivado por el recorte espacial y temporal de este estudio, hemos tratado de comprender la relación entre los clubes y la región de periódicos suburbanos.

Palabras clave: Fútbol. Periódicos. Historia.

\section{Referências}

A REUNIÃO de Hontem. Correio da Manhã, Rio de Janeiro, 17 de julho de 1918.

ATENÇÃO. O Suburbano, Rio de Janeiro, 1 de março de 1900.

BANGU. Bangú-Jornal, 21 de julho de 1918.

BARRETO, L. Uma conferencia esportiva, Careta, Rio de Janeiro, 1 de janeiro de 1921 .

DA GERAL para As Archibancadas. Correio da Manhã, 5 de maio de 1922. 
CHALHOUB, S. Trabalho, Lar e Botequim: o cotidiano dos trabalhadores no Rio de Janeiro da Belle Époque. Campinas: UNICAMP, 2001.

COM LICENÇA. Gazeta Suburbana, Rio de Janeiro, 15 de dezembro de 1883.

FERRÉS, J. Televisão subliminar: socializando através de comunicações despercebidas. Porto Alegre: Artmed, 1998.

FRANCO JÚNIOR, H. A dança dos deuses: futebol, sociedade, cultura. São Paulo: Companhia das Letras, 2007.

MENDONÇA, L. C. Nas margens: Experiência de suburbanos com periodismo no Rio de Janeiro (1880-1920). 2011. 149 f. Dissertação (Mestrado em História Social)-Instituto de Ciências Humanas e Filosofia, Departamento de História, Universidade Federal Fluminense, Niterói, 2011.

MOSCOVICI, S. Representações Sociais: investigações em psicologia social. 2. ed. Petrópolis/RJ: Vozes, 2004.

O ENCONTRO Bangu X S. Christovão Não Terminou... Correio da Manhã, 14 de julho de 1919.

O FLUMINENSE Derrotou o Bangu por 1 A 0. O Imparcial, 11 de junho de 1917.

O TÓPICO do "Bangú-Jornal". A Época, Rio de Janeiro, 18 de julho de 1918.

OS ACONTECIMENTOS de Domingo Ultimo no Bangu. O Imparcial, 13 de junho de 1917.

OS MATCHES de Hontem à Tarde. Correio da Manhã, 4 de maio de 1922.

PEREIRA, L. A. M. Footballmania: uma história social no Futebol do Rio de Janeiro: 1902-1938. Rio de Janeiro: Nova Fronteira, 2000.

POLlO, M. O incidente que provocou a invasão de campo, Correio da Manhã, Rio de Janeiro, 23 de outubro de 1916. 
RELPH, E. Place and Placelessness. Londres: Pion, 1980.

. Reflections on Place and Placelessness. Environmental \& Architectural Phenomenology Newsletter, v. 7, n. 3, 1996, p. 15-18.

HOBSBAWM, E. J. Mundos do trabalho: Novos estudos sobre história operária. Rio de Janeiro: Paz e Terra, 2008.

SANTOS JUNIOR, N. J. A construção do sentimento local: o futebol nos arrabaldes de Andaraí e Bangu (1914-1923). 2012. 126f. Dissertação (Mestrado em História Comparada)-Instituto de História, Universidade Federal do Rio de Janeiro, Rio de Janeiro, 2012.

SANTOS JUNIOR, N. J., MELO, V. A. Violentos e desordeiros: representações de dois clubes do subúrbio na imprensa carioca (década de 1910). Revista Brasileira de Educação Física e Esporte, São Paulo, v. 27, n. 3, p. 411-422, 2013.

SUBÚRBIOS... Correio Suburbano, Rio de Janeiro, 2 de março, 1895.

UMA CARTA Do Juiz desse Encontro. O Imparcial, 26 de novembro de 1919.

UMA NOTA Official do Andarahy. O Imparcial, 26 de novembro de 1919.

VIDA SPORTIVA. Bangú-Jornal, Rio de Janeiro, 14 de julho de 1918.

Recebido em: 18/12/2012

Revisado em: 21/02/2013

Aprovado em: 30/03/2013

Endereço para correspondência

edfnei@hotmail.com

Nei Jorge Santos Junior

Universidade Federal do Rio de Janeiro

Av. Pedro Calmon, $n^{\circ} 550$ -

Prédio da Reitoria, $2^{\circ}$ andar Cidade Universitária -

Rio de Janeiro, RJ - CEP 21941-901 